\title{
The implications of the new sulphur limits on the European Ro-Ro sector
}

\section{Zis, Thalis; Psaraftis, Harilaos N.}

Published in:

Transportation Research. Part D: Transport \& Environment

Link to article, DOI:

10.1016/j.trd.2017.03.010

Publication date:

2017

Document Version

Peer reviewed version

Link back to DTU Orbit

\section{Citation $(A P A)$ :}

Zis, T., \& Psaraftis, H. N. (2017). The implications of the new sulphur limits on the European Ro-Ro sector. Transportation Research. Part D: Transport \& Environment, 52, 185-201. https://doi.org/10.1016/j.trd.2017.03.010

\section{General rights}

Copyright and moral rights for the publications made accessible in the public portal are retained by the authors and/or other copyright owners and it is a condition of accessing publications that users recognise and abide by the legal requirements associated with these rights.

- Users may download and print one copy of any publication from the public portal for the purpose of private study or research.

- You may not further distribute the material or use it for any profit-making activity or commercial gain

- You may freely distribute the URL identifying the publication in the public portal 


\title{
The implications of the new sulphur limits on the European Ro-Ro sector
}

\author{
Thalis Zis ${ }^{\mathrm{a}, *}$, Harilaos N. Psaraftis ${ }^{\mathrm{a}}$ \\ ${ }^{a}$ Technical University of Denmark, Kgs. Lyngby, Denmark, tzis@dtu.dk \\ ${ }^{a}$ Technical University of Denmark, Kgs. Lyngby, Denmark, hnpsar@dtu.dk \\ ${ }^{*}$ Corresponding Author
}

\begin{abstract}
In an effort to reduce the environmental impacts of maritime transportation, the International Maritime Organization (IMO) designated special Sulphur Emission Control Areas (SECAs) where ships are required to use low-sulphur fuel. In January 2015, the sulphur limit within SECAs was lowered to $0.1 \%$, which can only be achieved if vessels are using pricier ultra-low sulphur fuel, or invest in abatement technologies. The increased operating costs borne by Ro-Ro operators in SECAs due to the stricter limits can result in the shutting down of some routes and a redistribution of cargo flows with land-based alternatives. The exact repercussions of the new sulphur limits are difficult to identify in the wake of significant recent reductions of the fuel prices for both lowsulphur and heavy fuel oil. This paper presents a modal split model that estimates modal shifts visa-vis competing maritime and land-based modes available to shippers. This allows examining the implications of the recent low prices to modal choice, and the influence a potential increase in fuel prices may have. The model is applied to seven routes affected by the regulation based on data from a leading European Ro-Ro operator. Sensitivity analyses on market share data, cargo values, freight rates, and haulers rates are conducted. Emissions inventories are constructed to assess the environmental efficacy of the SECA regulation. The novelty of the proposed model lies in the examination of the ex-post implications of shutting down a service and the redistribution of transport. Recommendations to mitigate and reverse the negative side-effects of such environmental legislation are proposed.
\end{abstract}




\section{Introduction}

Maritime transport plays a pivotal role in the global economy as it moves $80 \%$ of the worldwide trade cargo (UNCTAD, 2015). Ships offer economies of scale that constitute waterborne transportation the most cost-effective option, while at the same time the fuel efficiency of maritime transport per ton-kilometre is unrivalled.

\subsection{Environmental impacts of transport}

The transportation sector accounted for $22 \%$ of the world $\mathrm{CO}_{2}$ emissions in 2010 (IEA, 2014) while the maritime sector was responsible for $2.7 \%$ in 2007 (Buhaug et al., 2009), down to 2.2\% in 2012 (IMO, 2014). The respective figures for the European carbon footprint were at $20.1 \%$ in 2014 (up from 14.6\% in 1990), for the transportation sector (Eurostat, 2015); while the maritime sector was responsible for 4\% of the European $\mathrm{CO}_{2}$ emissions in 2013 (European Commission, 2013). These numbers agree with the notion that maritime shipping is the most environmentally friendly mode of transport in terms of carbon intensity. However, for other pollutant species a different situation exists due to the less clean bunker fuel used. One of the most pressing environmental issues associated with maritime transport is the high level of sulphur emissions from vessel activity. It is estimated that maritime shipping accounts for 5-8\% of the global anthropogenic $\mathrm{SO}_{2}$ emissions (Eyring et al., 2005), while PM emissions from shipping activities near coastlines have been linked with health impacts on nearby residents.

\subsubsection{The sulphur emission control areas}

To tackle the issue of sulphur emissions from shipping, the revised MARPOL Annex VI introduced limits on the maximum sulphur content allowed in bunker fuel used by ships (IMO, 2008). This regulation also designated emission control areas (SECAs) where progressively tighter limits applied. In 1997 the first SECA designated was the Baltic Sea, and was enforced after 2005, while the North Sea followed. The regulation stipulates that from 2020 onwards, the global limit of sulphur content will be $0.5 \%$ (outside SECAs), a decision that was confirmed at the $70^{\text {th }}$ session of IMO's Marine Environment Protection Committee (MEPC 70) in October 2016 after debate on low sulphur fuel availability. Cullinane and Bergqvist (2014) supported the further designation of SECAs due to the socio-economic benefits these would bring, while Panagakos et al. (2014) examined the implications of designating the Mediterranean Sea as a new SECA. The progression of sulphur limits within and outside SECAs is shown in Figure 1.

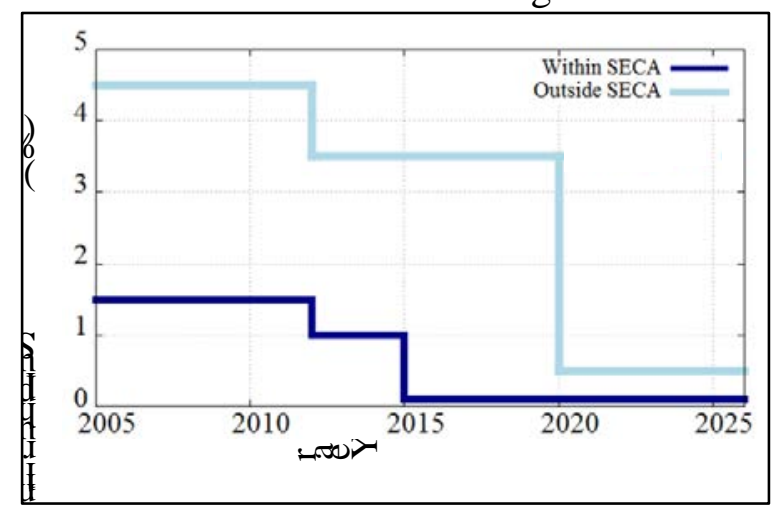

Figure 1: The Sulphur Limits Within and Outside SECAs

A crucial point in the timeline of the SECA regulation was the $1^{\text {st }}$ of January 2015 when the limit within SECA was drastically reduced to $0.1 \%$ from $1 \%$. The European Parliament and the Council 
(2005) had already set a limit of $0.1 \%$ sulphur content for ships sailing within inland waterways, and for port stays longer than 2 hours through the directive 2005/33/EC.

\subsection{Abatement options}

To secure compliance with the lower sulphur limits, ship operators can switch to low-sulphur fuel such as Marine Gas Oil (MGO) which is more expensive than the regular Heavy Fuel Oil (HFO) used before. Zis et al. (2015) noted that the use of MGO is offering a more flexible decision to ship operators who can continue operation as normal by switching when sailing in SECA regulated waters. This allows the introduction of speed optimization that result in lower sailing speeds within SECAs and higher outside. Furthermore, Fagerholt and Psaraftis (2015) proposed the ECA refraction problem whereby ships are trying to minimize the sailing distance travelled within the regulated waters.

Alternatively, ship operators can invest in technologies that allow the use of Liquefied Natural Gas (LNG), or retrofit their vessels with scrubber systems that allow the use of HFO. Scrubber systems essentially act as filters on the exhaust gases and neutralize the sulphur oxides achieving similar reductions. The LNG or scrubbers solutions have lower operating costs in comparison to use of MGO, however significant capital costs are required and a reasonable time for the vessel to stay in lay up during retrofitting. Zis et al. (2016) conducted a more detailed examination on the pros and cons of the various abatement options. They show that following the lower fuel prices observed in 2015, the payback period of scrubber investments has increased, rendering fuel switching more attractive. A relatively new option is the use of the new hybrid ultra-low sulphur fuel oil (ULSFO) products that comply with the regulation and offer the advantage of having a higher viscosity and better lubricity to MGO, with the same temperature requirements to HFO that allows the facilitation of fuel switching. In like manner to MGO, ULHFO fuel types are more expensive to regular HFO; however due to data availability this paper will consider as abatement options either the use of scrubber systems, or the use of MGO. Finally, it has to be noted that all options will lead to a reduction in $\mathrm{PM}$ emissions and not only $\mathrm{SO}_{\mathrm{x}}$. Therefore, a reduction in the external costs associated with health issues and fatalities of affected population residing near coastlines that are attributed to shipping emissions. However, these costs are not examined in this paper as the focus is on effects in the short sea shipping market.

\subsection{Implications of the new sulphur limits}

The anticipated increased operating costs due to more expensive fuel will not be absorbed entirely from the affected ship operators. These may be passed on to shippers by increasing freight rates for the affected voyages through bunker adjustment factors. Notteboom (2010) examined the anticipated impacts of the additional fuel costs due to the regulation on short sea shipping, and estimated that the response of the ship operators would be increased freight rates.

This can be particularly devastating to short sea shipping (SSS), as the increased freight rates may induce shippers to use land-based alternatives. As a result, certain routes may no longer be economically viable due to the increased operating costs and loss of market share, and as a result many ship operators may have to shut down certain services leading to even higher modal shifts. A modal shift from maritime modes to land-based options is against the targets of the European Union that promotes SSS for trading within the community.

Prior to 2015, there was anticipation for a modal shift for cargoes previously using ships sailing within SECA (Odgaard et al., 2013). However, recent evidence reveals that due to the current very low fuel prices this threat has not been realized, and ship operators reported outstanding positive financial figures in 2015. Despite this fact, fuel prices may again increase to their previous levels, and at the same time even if the current prices are low, the use of MGO or the previous investments 
on scrubbers have halted the drop in freight rates that is enjoyed in unaffected areas. Considering that more SECAs may be designated in the near future, and that the global cap of $0.5 \%$ will be enforced from 2020, it is necessary to understand the implications of the regulation on the modal choice for shippers.

\subsection{Structure of the paper}

This paper presents a modelling framework that can be used to examine the impacts of the SECA regulation on maritime routes that compete with land-based modes. The framework is applied on case studies using data from a leading Ro-Ro operator with services in the North and Baltic Sea. The next section presents a summary of the SSS sector and the main land-based alternatives for intra-European cargo. A modal split model is developed and calibrated based on market share data of the operator. The model allows the estimation of modal shifts when changes are introduced in the available options to the shipper. The results of the simulation are compared to the actual market response following the new limits, and sensitivity analyses are conducted to further comprehend the implications of the very low fuel prices observed during 2015. The paper finishes off with a discussion on the negative effects of the regulation, and the potential threats to the SSS sector should fuel prices increase.

\section{Short sea shipping in Europe}

The definition of what short sea shipping (SSS) is a difficult task and various approaches have been found in the literature. Short sea shipping can be considered as the transportation of people and goods through sea along a coast and without crossing an ocean or deep-sea waters, a term which is mainly associated with Europe (Bjornland, 1993).

\subsection{Freight transport statistics}

Ng et al. (2013) note that the European Commission has for long sought to promote SSS for trade within the Community as it:

- Offers an environmentally friendly and safe alternative to congested road networks

- Facilitates connections between Member states and can revitalise peripheral regions

- Can help meet the growing demand for transport due to the economic growth

In 2005, the EC reported that SSS and road transport both grew by 25\% between 1995 and 2002, with respective shares of $40 \%$ and $45 \%$ of all tonne-kilometres in Europe. Eurostat reported that SSS made up 58\% of the total EU-28 maritime transport of goods (the remaining being deep sea shipping), a figure which varied across reporting countries reaching peaks of more than $80 \%$ in certain countries. According to Eurostat $32.3 \%$ of the tonne-kilometres performed in the intra-EU trade was seaborne in 2008.The EC (2015) estimated that $31.3 \%$ of intra-EU goods transport was maritime, $11.7 \%$ used inland waterways, while road transport increased to $49.4 \%$ The EU seeks to continue supporting the development of SSS in order to reduce road congestion by moving approximately $30 \%$ of road freight on distances longer than $300 \mathrm{~km}$. This modal shift may help meet the target of reducing transport-related greenhouse gas emissions by $60 \%$. As road transport within EU benefits from reduced bureaucracy and simpler administrative procedures, regulations such as the SECA new lower sulphur limit can reduce the advantages of SSS in Europe and lead to undesirable modal shifts. 


\subsection{The market before and after the new SECA limit}

This section will contrast the anticipated impacts of the lowered sulphur limit in the European SSS sector, with the aftermath of the first year of its implementation and discuss the role of bunker fuel price during this period.

\subsubsection{Ex-ante technical studies on the SECA regulation}

Some ship operators started investing in scrubber systems some years before the new limit, so as to be prepared for the new regulation. The European Commission as part of the Motorways of the Seas programme provided subsidies to help with the capital investment costs, reaching up to $20 \%$ of the total installation costs, a subsidy that has increased to 30\% as of 2014. Jiang et al. (2014) performed a cost-benefit analysis study to compare investments in scrubber systems with the use of lowsulphur fuel, and conclude that scrubber systems were suitable for vessels with a remaining lifespan of more than four years with the fuel prices at the time. Lemper et al. (2009) predicted modal shifts of on average $22 \%$ after 2015, and expected increased freight rates for various fuel scenarios. However, there had been no fuel price scenarios that predicted the actual drop of fuel prices in 2015.

\subsubsection{Fuel prices}

Prior to 2015 there were concerns that the much higher fuel prices would constitute several services operating within SECA as unprofitable and could lead to severe modal shifts to road mode. Figure 2 presents the fuel price (USD/ton) fluctuation for MGO and HFO.

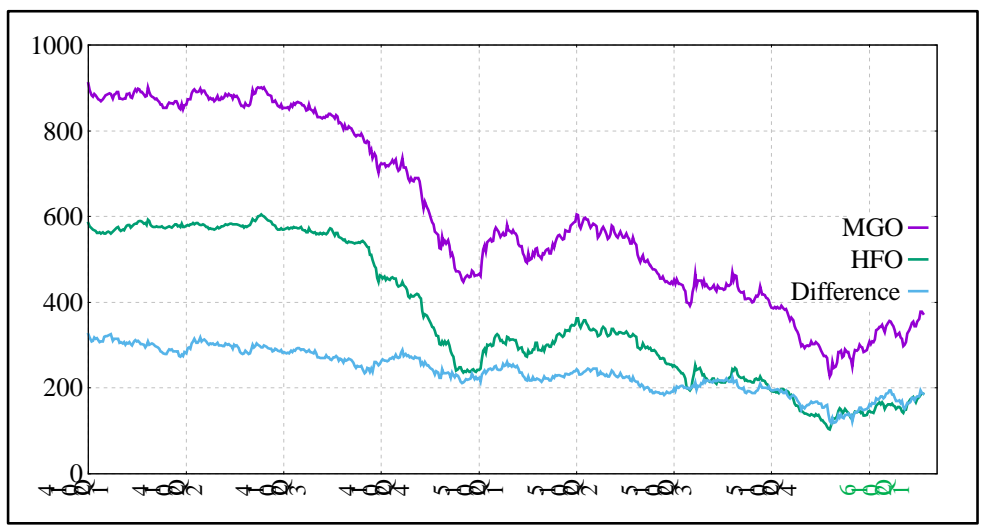

Figure 2: Fuel Prices for MGO and HFO, and the Price Differential. Data Source: www.Bunkerworld.com (2016)

It can be observed that during 2015 when the lowered limit was imposed, the fuel price for MGO was actually lower than the cost of HFO used in 2014. This fact hints that the negative implications of the regulation were masked by the surprisingly low fuel prices that actually lowered the operating costs for the ship operators. This could lead to lower freight rates for all transport modes.

\subsubsection{The aftermath of the lower SECA limit}

Despite the concerns of the Ro-Ro sector that certain routes would be closed as a consequence of the new limit, most operators saw a very positive year in 2015. De Boer et al. (2016) noted that the competitive position of Ro-Ro shipping with road transport has worsened, due to the lower fuel price differential between road diesel and marine fuel. A recent survey circulated on ship operators revealed that most did not report any modal shifts, though it may be too early to quantify the behaviour of customers after the new limit (Verhoeven, 2015). Therefore, the anticipated negative impacts of the regulation have not been realized yet, following a very positive financial year in 2015 for most operators. However, this is symptomatic and can be mainly attributed to the lowest 
fuel prices recorded in 15 years. It is therefore necessary to understand the implications of the low fuel prices to the observed picture, and what would the situation be if either:

- The regulation was not present and ship operators could still use HFO considering the low 2015 prices, or

- The MGO fuel prices returned to the previous high levels considering 2014 prices

Particularly the second scenario is not unlikely as seen in Figure 2 and the increased fuel prices in the first quarter of 2016, a trend which if continued could have major implications on modal shifts towards land-based options. The latter, constitutes the need for accurate modelling tools imperative in order to understand the near-future implications of policy regulations on the maritime sector.

\section{Methodology}

This section presents the modelling framework used in the subsequent scenario analysis. A twostage model is proposed, where at first the probability of selecting an available transport mode is calibrated based on actual market share. A secondary model is assessing the implications of modal shifts on the ship operator's profitability, and the environmental balance. The methodological framework depicted schematically in Figure 3, allows the consideration of policy measures and operating practices in the following events:

- The environmental balance has deteriorated due to increased emissions per transported unit of cargo, as a result of modal shifts and changes in capacity utilization rates

- The profitability of the ship operator drops dramatically and either a certain service has to be shut-down or its characteristics be drastically changed. 


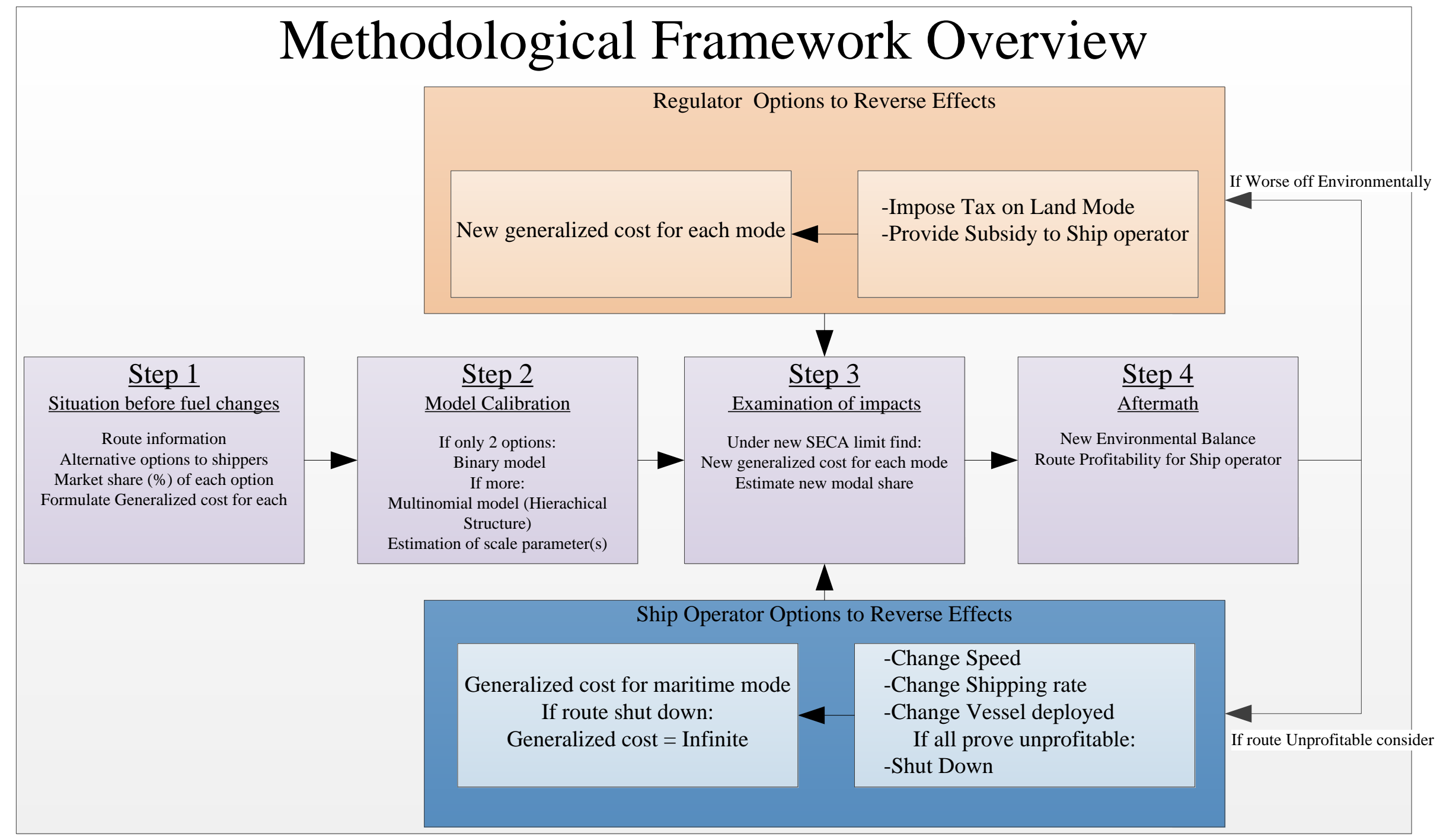

Figure 3: The Process of Examining the Impacts of the New Sulphur Limits on Ro-Ro Shipping 


\subsection{The modal split model}

The first step for the development of the model is the identification of all available transport options between certain O-D pairs, and gathering information on the transported volumes for each option. In this work, it is assumed that the shipper must first decide whether to make use of a maritime mode, or only opt for a fully land-based option. Subsequently, the shipper must decide which variant mode to choose. This is shown in Figure 4 where there are two maritime modes (company A vs company B) and two different land-based options.

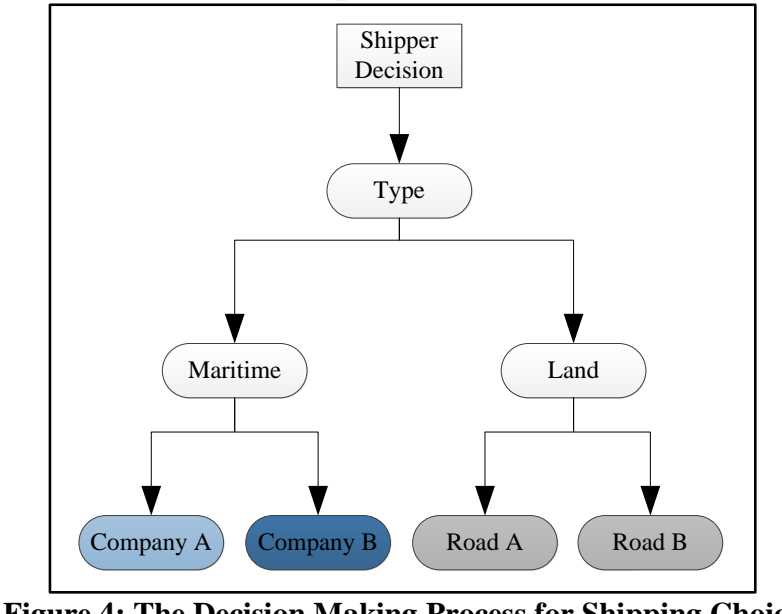

Figure 4: The Decision Making Process for Shipping Choice

\subsection{Generalized cost formulation}

The shipper's decision is based on certain parameters, which for simplicity are assumed to be the cost of transport for each option, and the total travel time. There may be additional factors that influence the shipper's choice (e.g. reliability of service, number of modal changes, a strong preference to a particular mode, etc.) These can be transformed to additional monetary costs or travel time penalties, but require significant amounts of data to accurately translate their time and cost implications. This work considers that the shipper's decision is based on the generalized cost of transport $G C_{i}(€)$ for each mode $i$ as in:

$G C_{i}=T C_{i}+a \cdot T T_{i}$

where $T C_{i}\left(€ /\right.$ lanemeter-lm) is the monetary travel cost for mode $i$ and $T T_{i}$ (hours) is the total travel time. The cost is expressed in $€$ per lanemeters as this is the unit in which Ro-Ro operators are setting freight rates.

Parameter $\alpha(€ / \mathrm{lm} \cdot$ hour $)$ represents the monetary value of time that links the previous two as formulated by Psaraftis and Kontovas (2010). This paper considers that the value of time is a function of the cargo value $C V(€ / \mathrm{lm})$ and its opportunity cost of capital $r(\%)$ as in:

$a=\frac{C V \cdot r}{365 \cdot 24}$

\subsection{Calibration of mode choice}

Logistical regression models (logit models) are frequently used to determine the number of trips on different modes between the various O-D pairs. The underlying assumption of such models is that the probability of choosing an option is linked to the probability that the perceived disutility of that 
option is lesser than the other available modes. In this work, the generalized cost of transport is considered as this disutility. Binary logit models in the context of maritime vs land-based modes have been applied in recent literature (Panagakos et al., 2014). This paper enhances the previous methodologies by considering a hierarchical model structure as in Ortuzar and Willumsen (1994) that better reflects the actual number of available options to the shipper (as in Figure 4). Therefore, the calibration is also conducted in two steps for routes where more options are available.

\subsubsection{The first split: Maritime vs Land-based}

It is assumed that there are $M$ predominantly maritime modes and $L$ fully-land-based modes. The probability of choosing any maritime mode $m \in M$ is given by:

$P_{i}=\frac{e^{-\lambda_{1} \cdot G C_{i}}}{\sum_{i=M, L} e^{-\lambda_{1} \cdot G C_{i}}}$

where $\lambda_{1}$ is a dispersion parameter to be estimated using the calibration data. This acts as a weight attached in the choice to the generalized cost. The larger the value of $\lambda_{1}$, the greater the implication of a change in the cost of one option to the decision. In equation 3, the $G C_{M}$ and $G C_{L}$ terms refer to the composite generalized cost of each nest (maritime vs land-based). These are functions of the generalized costs of all alternatives within each nest.

\subsubsection{The second split and estimation of composite costs}

Following the initial decision to select a nest comprising of correlated transport options, the shipper has to decide which one of the available $m \in M$ (or $l \in L$ ) to use. The probability of choosing mode $\mathrm{j}$, when nest $i \in\{M, L\}$ is selected is:

$P_{j / i}=\frac{e^{-\lambda_{i} \cdot G C_{j / i}}}{\sum_{\mathrm{j} \in \mathrm{i}} e^{-\lambda_{i} \cdot G C_{j / i}}}$

where $\lambda_{i} \in\left\{\lambda_{M}, \lambda_{L}\right\}$ is a dispersion parameter for the secondary split (within the maritime $M$ or the landbased $L$ nest) and can be calibrated if the generalized cost $G C_{j / i}$ and the respective market shares of all options within the nest are known. Finally, the composite generalized cost which is necessary for the calibration of the first split is given by:

$G C_{i}=\frac{-1}{\lambda_{i}} \log \left(\sum_{\mathrm{j} \in \mathrm{i}} e^{-\lambda_{i} \cdot G C_{j / i}}\right)$

From (5) follows that if there is only one alternative $j$ within a nest $i$, then the composite cost collapses into the generalized cost $G C_{j}$. If there are two alternatives (one maritime and one landbased) then the model collapses into a binary logit model. Therefore, the structure can be applied to case studies for all combinations of available options such as:

- Routes that face no competition from land-based modes, but have more maritime operators

- Routes with a unique shipping operator and one land-based alternative

- A combination of the previous 


\subsection{Estimating modal shifts in absence of data}

In the methodology described in the previous sections, it is clear that in order to accurately calibrate the model it is necessary to obtain comprehensive data on the actual transported volumes for all available modes, including all distance O-D pairs, freight rates, and cargo value for each shipment transported. This is not always possible especially when the period of interest is narrow, and also considering the scarcity of relevant data particularly for haulers transportation statistics. In this paper, the focus is on the immediate repercussions of the lower sulphur limit, and as such the calibration is to be performed based on data for 2014, while the simulation is for 2015. At the same time, statistical bodies such as Eurostat provide aggregate estimates on transported volumes within the EU, that are not updated as often. During the development of this model, the Ro-Ro operator provided data on the actual transported cargo volumes for the two years examined. However, the shipping company is not able to provide disaggregate level data on actual O-D pairs, and value of cargo transported. In Ro-Ro shipping, the freight rates are a function of lanemeters, thus the actual volume that the cargo occupies onboard the vessel. As such, with the exception of dangerous cargo (where a different pricing policy applies) the shipping company is not always aware of the value of the transported goods. The model can be still useful in predicting modal shifts even in the absence of all the required data so long as the change in generalized cost is known. Therefore, the implications of the new sulphur limit on the freight rates for the shipping company will be used to assess the change in the probability of a shipper to select the same mode of transport for its cargo.

\subsubsection{Elimination of the scale parameter in predicting modal shifts}

Considering a binary case between a maritime $m$ and a land-based $l$ option, let $G C_{m}$ and $G C_{l}$ be the respective generalized costs of transport used in the calibration. As stated in earlier sections, the scale parameter $\lambda$ can be calibrated if the market shares of each option $x_{m}$ and $x_{l}$ respectively are known. In this subsection these are assumed to be unknown. Let now $G C_{m}^{\prime}$ and $G C_{l}^{\prime}$ to denote the new generalized cost for each option following a change in the cost or travel time (or both). The objective in this case is to estimate the new market shares $x_{m}^{\prime}$ and $x_{l}^{\prime}$. It is possible to eliminate the unknown scale parameter $l$ if equation 4 is used for both cases (before and after the introduction of changes) considering the following system:

$$
\left\{\begin{aligned}
x_{m} & =\frac{e^{-\lambda \cdot G C_{m}}}{e^{-\lambda \cdot G C_{m}}+e^{-\lambda \cdot G C_{l}}} \\
x_{l} & =\frac{e^{-\lambda \cdot G C_{l}}}{e^{-\lambda \cdot G C_{m}+e^{-\lambda \cdot G C_{l}}}} \\
x_{m}^{\prime} & =\frac{e^{-\lambda \cdot G C_{m}}}{e^{-\lambda \cdot G C_{m}^{\prime}}+e^{-\lambda \cdot G C_{l}^{\prime}}} \\
x_{l}^{\prime} & =\frac{e^{-\lambda \cdot G C_{l}^{\prime}}}{e^{-\lambda \cdot G C_{m}^{\prime}}+e^{-\lambda \cdot G C_{l}^{\prime}}}
\end{aligned}\right.
$$

Dividing equation 6.1 over 6.2 and equation 6.3 over 6.4 , and taking logarithms for each new equation gives: 
$\left\{\begin{array}{l}\ln \left(\frac{x_{m}}{x_{l}}\right)=-\lambda\left(G C_{m}-G C_{l}\right) \\ \ln \left(\frac{x_{m}^{\prime}}{x_{l}^{\prime}}\right)=-\lambda\left(G C_{m}^{\prime}-G C_{l}^{\prime}\right)\end{array}\right.$

Finally, dividing 6.5 over 6.6 allows the elimination of the scale parameter, and thus the expression of the new market shares as a function of the generalized cost differentials $\Delta G C$ and $\Delta G C^{\prime}$, leading to equation 7 :

$\frac{x_{m}^{\prime}}{x_{l}^{\prime}}=\left(\frac{x_{m}}{x_{l}}\right)^{\frac{\Delta G C^{\prime}}{\Delta G C}}$

Considering that the market shares $x_{m}$ and $x_{l}$ add up to the total transported volumes (or to 1 if these are treated as probability of choosing a mode), it is possible to estimate the impacts of the new changes in the probability of selecting each of the affected modes. This theoretical approach can also be used in cases where more than two options are available, and accurate information on the market shares is not retrieved.

\subsubsection{Simulation using meaningful ranges}

The second approach which is used in the subsequent case study analysis is the simulation of data considering certain ranges in which the required data take values. Under this approach, it is expected that some information is known on aggregate terms, and simulation is then used to compare the modal shifts for various combinations of the examined parameters. It is then possible to construct a 'map' that shows all possible combinations for different input values, and thus when more accurate data are retrieved to use this to estimate the impacts of a given policy. This approach is used in this paper following discussions with relevant industry experts to identify meaningful ranges for the values used in the simulations. For each of the routes examined, a simulation of approximately 4000 different combinations of input parameters is executed, and the average modal shifts are presented, also showing the interquartile ranges (IQR) for these results. These are presented in the next section.

\section{Analysis}

The case studies in this section are based on the network of a leading Ro-Ro operator in the North Sea and the Baltic, which has provided the necessary data for the application of the model. The operator operated 18 routes in 2015. The operator has provided data on transported cargoes for 2014 and 2015, fleet assignment, fuel consumption, and revenue for each route. The subsequent analysis focuses on a subset of seven routes, the selection criteria for which are discussed in the next section.

\subsection{Selected routes}

\subsubsection{Route selection criteria}

The route selection criteria were the following:

- geographical balance

- chain configuration (sailing distance and frequency)

- Deployed capacity

- Commodity mixture

- Vessel types (Ro-Pax vs Ro-Ro), and abatement option (scrubbers vs MGO)

- Data availability 
The selected routes were divided according to their geographical location into three groups; North Sea (blue), Baltic Sea (burgundy), Cross-Channel (grey) routes. The routes are shown in Figure 5, and a short description of their characteristics follows.

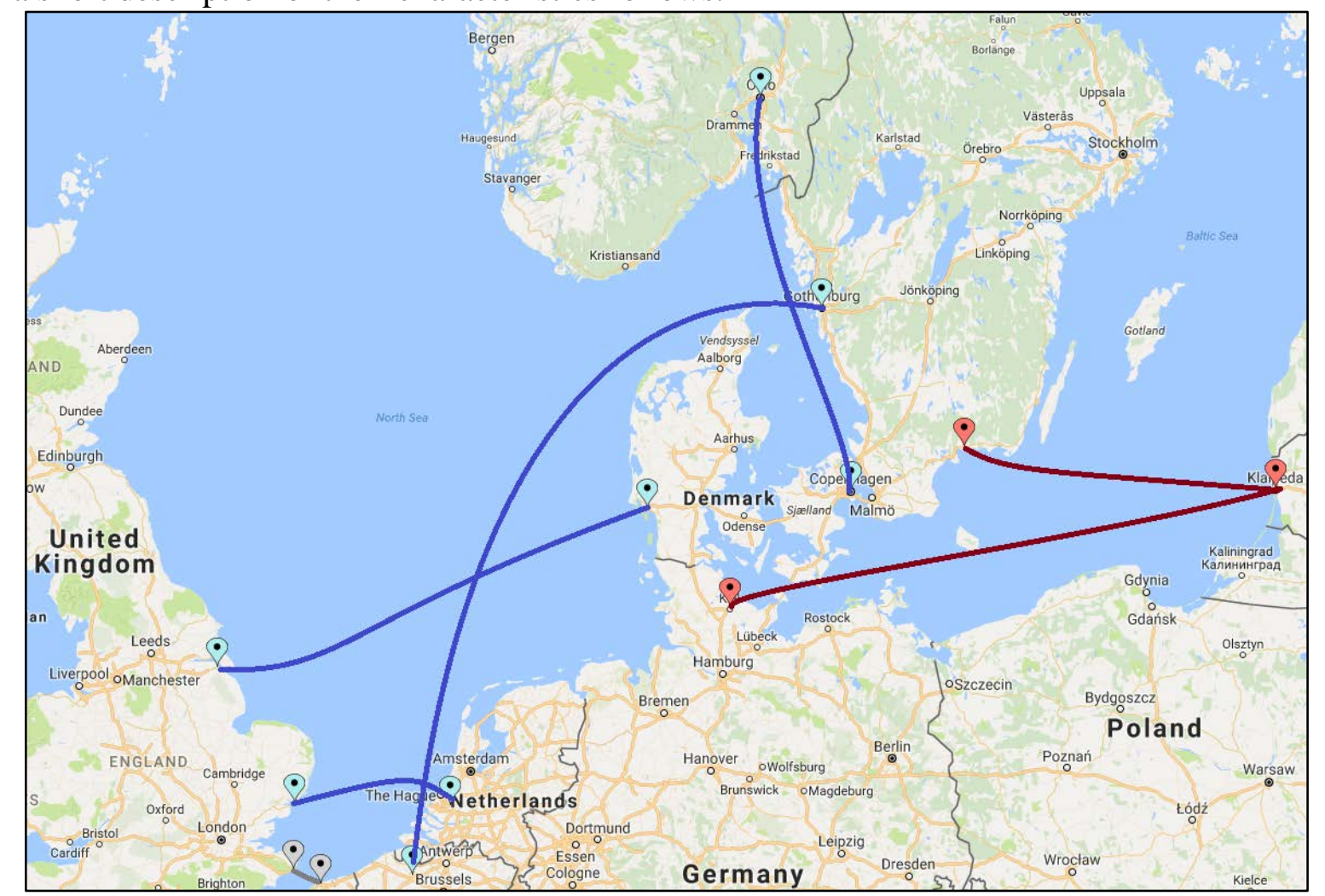

Figure 5: The selected SSS routes for analysis

- Gothenburg - Ghent (Ro-Ro - North Sea)

This route is connecting Sweden with Belgium with six sailings per week, using Ro-Ro ferries that have been retrofitted with scrubbers. It faces competition from fully land-based modes (using the Øresund Bridge to cross from Sweden to Denmark). There are certain services from Gothenburg to other European ports that can considered as viable alternatives, but this paper only considers a competing maritime link from Gothenburg to Kiel.

- Esbjerg - Immingham (Ro-Ro - North Sea)

This high frequency service connects the UK with Jutland in Denmark. This route competes with fully land-based modes (with the exception of the Cross-Channel passage by rail or ferry), and while there are additional maritime links that could substitute the link, the paper considers only this maritime link.

- Rotterdam - Felixstowe (Ro-Ro - North Sea)

This service connects the UK with the Netherlands. The vessels are only transporting cargoes, and there is a high sailing frequency for a relatively short sea passage.

- Copenhagen - Oslo (Pax - North Sea)

This is considered a cruise route, which is mainly focused on passenger traffic. However, the paper focuses on the effects on cargoes, and will consider a land-based alternative for the cargoes using the Øresund bridge to cross to Sweden.

- $\quad$ Klaipeda - Kiel (Ro-Pax - Baltic Sea) 
This service is directly competing with fully land-based alternatives due to the geography of the two ports and the lack of other maritime services. There is a mixture of vessels equipped with scrubbers and vessels relying on MGO deployed in this route. Some of the revenue generated on this route stems from passenger traffic.

- $\quad$ Klaipeda - Karlshamn (Ro-Pax - Baltic Sea)

This service is not facing competition from other ferry links, while a fully land-based option is significantly longer, which constitutes the service interesting in comparison to other examined routes.

- Dover - Calais (Ro-Pax - Cross Channel)

This service connects the United Kingdom with continental Europe through a very short sea passage. There had been more maritime services on this route; however during 2015 there have been many disruptions due to a maritime operator's bankruptcy which led to severe strikes. Approximately a quarter of the generated revenue was attributed to passengers. In this paper the competition of the route is limited to the Eurotunnel rail underwater passage.

\subsubsection{Summary of transported volumes}

The Ro-Ro operator has provided aggregate annual data on the number of trips, the transported cargo (in lanemeters), the freight rates, and the fuel consumption for all vessels for each of the seven examined services. The summary of these data is shown in Table 1, using percentage changes between the two years due to confidentiality of data. In addition, during these two years a total number of 24 vessels were used in these seven routes, 15 of which were equipped with scrubbers.

Table 1: Overview of Changes in Transported Cargoes in the Examined Routes. Source: own analysis based on data provided by the Ro-Ro operator

\begin{tabular}{|c|c|c|c|c|c|c|}
\hline Route & Year & $\begin{array}{l}\text { Trips } \\
\text { Total }\end{array}$ & $\begin{array}{c}\text { Transported } \\
\text { Cargo } \\
\text { Volume } \\
\text { change (\%) }\end{array}$ & $\begin{array}{c}\text { Cargo } \\
\text { Rate } \\
\text { change } \\
(\%)\end{array}$ & $\begin{array}{c}\text { Revenue } \\
\text { Change } \\
(\%)\end{array}$ & $\begin{array}{c}\text { Annual } \\
\text { Fuel } \\
\text { Cost } \\
\text { Change } \\
(\%) \\
\end{array}$ \\
\hline $\begin{array}{c}\text { Gothenburg } \\
\text { Ghent }\end{array}$ & $\begin{array}{l}2014 \\
2015\end{array}$ & $\begin{array}{l}553 \\
569\end{array}$ & 6.06 & -5.62 & 0.09 & -52.89 \\
\hline $\begin{array}{c}\text { Esbjerg } \\
\text { Immingham }\end{array}$ & $\begin{array}{l}2014 \\
2015\end{array}$ & $\begin{array}{l}512 \\
580\end{array}$ & 19.46 & -0.5 & 18.85 & -15.29 \\
\hline $\begin{array}{l}\text { Rotterdam } \\
\text { Felixstowe }\end{array}$ & $\begin{array}{l}2014 \\
2015\end{array}$ & $\begin{array}{l}1514 \\
1637\end{array}$ & 15.13 & 0.5 & 15.71 & -24.34 \\
\hline $\begin{array}{c}\text { Copenhagen } \\
\text { Oslo }\end{array}$ & $\begin{array}{l}2014 \\
2015\end{array}$ & $\begin{array}{l}687 \\
702\end{array}$ & -5.82 & 1.58 & 4.28 & -9.36 \\
\hline $\begin{array}{c}\text { Klaipeda } \\
\text { Kiel }\end{array}$ & $\begin{array}{l}2014 \\
2015\end{array}$ & $\begin{array}{l}611 \\
615\end{array}$ & -4.64 & -7.71 & -8.89 & -30.05 \\
\hline $\begin{array}{c}\text { Klaipeda } \\
\text { Karlshamn }\end{array}$ & $\begin{array}{l}2014 \\
2015\end{array}$ & $\begin{array}{l}717 \\
710\end{array}$ & 3.64 & -2.32 & 3.73 & -22.99 \\
\hline $\begin{array}{l}\text { Dover } \\
\text { Calais }\end{array}$ & $\begin{array}{l}2014 \\
2015\end{array}$ & $\begin{array}{l}6210 \\
4994\end{array}$ & -17.66 & 9.36 & -18.04 & -50.35 \\
\hline
\end{tabular}

For all routes the fleet deployment has improved as the freight utilization rate has increased for all cases with the exception of Copenhagen-Oslo, which is considered predominantly a passenger route. It is noteworthy that one Baltic service shows decreased revenue, however it has to be taken into account that operating costs have decreased at a much higher rate due to the lower fuel costs. 
The Dover-Calais route shows the poorest financial performance (highest revenue reduction), however this is mainly attributed to the lower sailing frequency due to external events affecting this service in the beginning of 2015, with strikes due to closure of a competing service, as well as disruptions to the service due to protests of immigrants. In terms of fuel costs, it is evident that these have decreased for all routes. More interesting conclusions can be drawn by the Gothenburg Ghent route where all deployed vessels were using scrubbers in both years. This fuel costs reduction is essentially what would have been enjoyed at all routes, if HFO was still allowed as in 2014. In contrast, the only route where all vessels were running on MGO was Dover - Calais, and the lower fuel costs are a consequence of the reduced number of trips in 2015, and the very low fuel prices. The reduction is lesser in other routes due to some of the vessels switching to MGO which while still cheaper than HFO in 2014, it is more expensive than HFO (2015 prices). However, it can be seen that the profitability of all routes has improved as the fuel costs have reduced at higher rates than revenue from freight transported (which has also increased for most routes). The profitability of the Ro-Pax services is also depending on passenger traffic, and while passenger traffic is not modelled in this paper the data from the Ro-Ro operator showed smaller fluctuations in passenger traffic. Modelling passenger demand before and after the new sulphur limit is a more difficult task, as stated preference methodologies should be used which is beyond the scope of this work.

\subsection{Model Calibration for all links}

Based on the actual transported volumes in 2014, the modal split model can be calibrated for a range of scenarios on the seven selected routes. As information on the actual overall demand between certain O-D pairs was not retrieved for 2014, a simulation approach has been used to account for the market shares of land-based options considering different ranges. The central value for the market shares of each option is assumed following discussions with relevant industry experts, and aggregate information available in Eurostat, and the Shippax CFI journal with ferry transportation statistics for trailers and passengers.

For the first Route a hierarchical structure is used assuming that the two maritime options are correlated. For the other two routes the modal split model collapses to a binary version. It is assumed that the opportunity cost of capital for the cargo depreciation is 3\% (the central value of the range used in the sensitivity analysis). The freight rate for road links is taken at $0.022 € / \mathrm{km}$ for each $\mathrm{lm}$ transported using a simplistic conversion of a freight cost per trailer into lanemeters (a trailer is $14 \mathrm{~m}$ long), and an average road speed of $70 \mathrm{~km} / \mathrm{h}$ is assumed as in Panagakos et al. (2014). Intermodal changes are assumed to require 2 hours at each port. Finally, for cargo values a simulation approach is used for a wide range of commodities from $100 €$ to $10000 €$ per $\operatorname{lm}$ of cargo. The road distances are calculated using a GIS tool. The calibration results are summarized in Table 2. 
Table 2: The Baseline Case and the Calibration Results

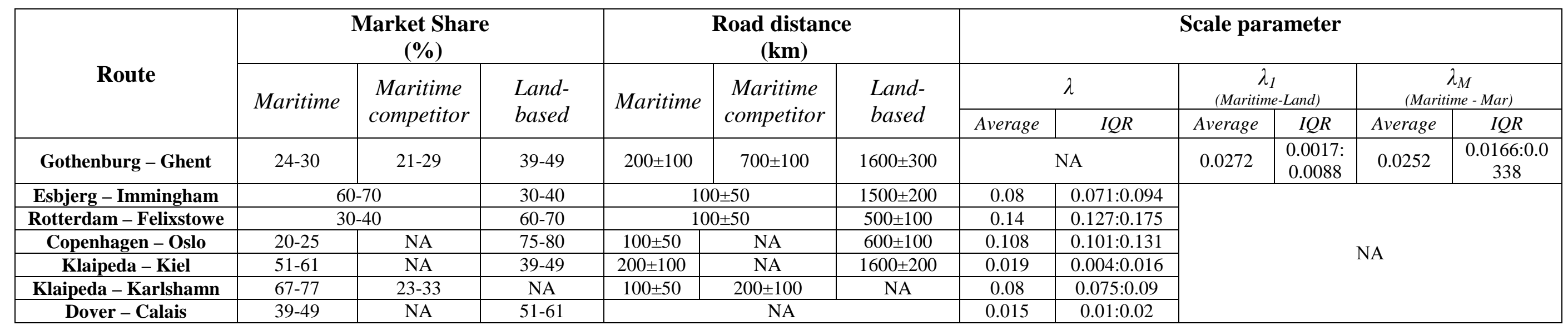


The dispersion parameter values for the runs vary as revealed from the standard deviation for each case. The average values shown are based on using the central values for each parameter, and are shown to agree with the dispersion parameter values for freight transport of previous studies (Panagakos et al., 2014; Lemper et al., 2009). As discussed in section 3.3.1, larger values for the scale parameters indicate a bigger shift potential following changes in the utility (generalized cost) of the available options. This can be interpreted in the following manner; if the generalized cost of the maritime option is increased by the same amount in all seven routes assuming all other modes are not changing their cost, the loss of cargo will be higher for the route with the higher scale parameter value. According to the results of Table 2, the Rotterdam-Felixstowe route is more elastic to changes while the Gothenburg-Ghent and Dover-Calais appear to be the more resilient route to changes. This observation is consistent with the figures of Table 1, where the Rotterdam-Felixstowe route is showing a significant increase in transported volumes despite the very finite change in freight rates.

\subsection{The fuel price scenarios}

The benchmark period for all route scenarios is 2014, the last year before the introduction of the new limit. The fuel prices scenarios are considering the average price of fuel during 2014 as the benchmark, and the simulation is performed for three scenarios of fuel prices in 2015.

\subsubsection{Fuel Case 1}

Fuel Case 1 is referring to the actual fuel price difference that the ship operators faced, and thus the change in freight rates that the shippers experienced. This will allow comparing the findings of the model, with the actual change in demand due to the fuel prices in 2015 and thus concluding whether the modal split methodology used is a reasonable approach.

\subsubsection{Fuel Case 2}

Fuel Case 2 is a hypothetical scenario to illustrate what the impacts of the regulation would have been, if the prices had not unexpectedly dropped to the point that it was actually cheaper to use MGO in 2015 as compared to HFO in 2014. For this reason, the MGO fuel prices in 2014 are used to simulate the effects of the regulation as anticipated in the ex-post market and research reports.

\subsubsection{Fuel Case 3}

Fuel Case 3 is a hypothetical scenario of what would have happened if the sulphur limit had remained at $1 \%$ and thus the only difference in operating costs would be the change in fuel prices as a result of the market. It has to be noted that in this case, the investments in scrubber systems would have not taken place, and thus the fuel consumption of the vessels must be adjusted to account for this fact.

\subsubsection{Fuel Price and Relationship with Freight Rates}

The freight rates are influenced by the fuel price at each period through the bunker adjustment factor (BAF). Ship operators are required by the European Commission to publish their methods for calculating the BAF, and each operator has to set its own independent BAF. The BAF takes into account the fuel change by including the fuel price difference between MGO and HFO. However, due to the low fuel prices in 2015 there have been services where the freight rates have decreased. A decrease in freight rates from haulers could have been observed, however not enough data were found on haulers rates in Europe between 2014 and 2015.

\subsection{Simulation results}

Simulations were conducted for a range of inputs including variations on: 
- dispersion parameters (based on the model calibration of section 4.2 and ranges in Table 2),

- road distances for each maritime option,

- new freight rate for land-based options,

- cargo values,

- depreciation rate.

The results of the simulations are summarized in Table 3. Table 3 shows the average change in the market share of each option for the three fuel case scenarios. In other words Table 3 summarizes what gain or loss of the total market share each option faces with the new freight rates in 2015. Table 3 also presents the change in the probability of choosing each available option; this essentially indicates the anticipated change in transport demand for each option. It has to be noted that for the other maritime options the freight rates are assumed not to change for any fuel case scenario. This assumption was necessary due to the lack of data on the specification of freight rates for the competing operators. With regards to the road transportation costs, the assumption is that these are changing at a lower rate than the maritime freight rates, but follow the trends of fuel costs. The rationale behind this assumption is that the low-sulphur limits are an additional burden that only maritime operators are facing. In the simulations, ranges of new haulers freight rates were used. The results of Table 3 are therefore indicative of the implications of the new sulphur limit, as they examine modal shifts for a wide range of scenarios using different parameter combinations. Table 3 shows the interquartile range of the change in the market share of each available option, based on the results of all simulation runs. The variation is notable, and is primarily attributed to the variations of the scale parameter values that were used in the simulation, ergo, there is an associated risk when predicting the ex-post market shares of the transportation options that are being modelled. The scale parameters can be estimated with higher accuracy when the information on baseline market shares is more precise. 
Table 3: Modal Shifts for all Routes in the Three Fuel Case Scenarios

\begin{tabular}{|c|c|c|c|c|c|c|c|c|c|c|}
\hline \multirow{4}{*}{ Route } & \multirow{4}{*}{$\begin{array}{c}\text { Fuel } \\
\text { Case } \\
\text { Scenario }\end{array}$} & \multicolumn{9}{|c|}{ New Shares } \\
\hline & & \multicolumn{6}{|c|}{ \% Market share change } & \multicolumn{3}{|c|}{ Probability of choosing option change (\%) } \\
\hline & & \multicolumn{2}{|c|}{ Maritime } & \multicolumn{2}{|c|}{$\begin{array}{c}\text { Maritime } \\
\text { competitor }\end{array}$} & \multicolumn{2}{|c|}{ Land-based } & \multirow{2}{*}{ Maritime } & \multirow{2}{*}{$\begin{array}{c}\text { Maritime } \\
\text { competitor }\end{array}$} & \multirow[t]{2}{*}{ Land-based } \\
\hline & & Average & $I Q R$ & Average & $I Q R$ & Average & $I Q R$ & & & \\
\hline \multirow{3}{*}{ Gothenburg - Ghent } & 1 & 1.23 & 1.09:1.56 & -1.02 & $-0.95:-1.21$ & -0.22 & $-0.06:-0.37$ & 3.98 & -4.71 & -0.47 \\
\hline & 2 & -1.02 & $-0.49:-1.05$ & 0.44 & $0.37: 0.8$ & 0.58 & $0.05: 0.25$ & -3.34 & 2.04 & 1.35 \\
\hline & 3 & 1.68 & $1.38: 2.15$ & -1.05 & $-0.76:-1.67$ & -0.63 & $-0.08:-0.44$ & 5.56 & -4.73 & -1.38 \\
\hline \multirow{3}{*}{ Esbjerg - Immingham } & 1 & 0.94 & 0.92:1.09 & \multirow{3}{*}{\multicolumn{2}{|c|}{ NA }} & -0.94 & $-0.92:-1.09$ & 1.53 & \multirow{3}{*}{ NA } & -2.4 \\
\hline & 2 & -1.13 & $-0.62:-0.81$ & & & 1.13 & $0.62: 0.81$ & -1.13 & & 1.99 \\
\hline & 3 & 1.55 & $1.44: 1.82$ & & & -1.55 & $-1.44:-1.82$ & 2.49 & & -4.18 \\
\hline \multirow{3}{*}{ Rotterdam - Felixstowe } & 1 & 0.93 & 0.08:1.93 & \multirow{3}{*}{\multicolumn{2}{|c|}{ NA }} & -0.93 & $-0.08:-1.93$ & 2.89 & \multirow{3}{*}{ NA } & -1.36 \\
\hline & 2 & -0.59 & $-0.51:-0.72$ & & & 0.59 & $0.51: 0.72$ & -1.85 & & 0.89 \\
\hline & 3 & 1.84 & $1.84: 2.13$ & & & -1.84 & $-1.84:-2.13$ & 5.85 & & -2.67 \\
\hline \multirow{3}{*}{ Copenhagen - Oslo } & 1 & -1.76 & $-1.62:-2.1$ & \multirow{3}{*}{\multicolumn{2}{|c|}{ NA }} & 1.76 & 1.62:2.1 & -8.24 & \multirow{3}{*}{ NA } & 2.25 \\
\hline & 2 & -2.64 & -1.54:-3.54 & & & 2.64 & $1.54: 3.54$ & -11.07 & & 3.64 \\
\hline & 3 & -0.89 & $-1.04:-1.57$ & & & 0.89 & $1.04: 1.57$ & -5.19 & & 0.93 \\
\hline \multirow{3}{*}{ Klaipeda - Kiel } & 1 & -0.29 & -0.08:-0.29 & \multirow{3}{*}{\multicolumn{2}{|c|}{ NA }} & 0.29 & 0.08:0.29 & -0.62 & \multirow{3}{*}{ NA } & 0.55 \\
\hline & 2 & -0.73 & -0.16:-0.64 & & & 0.73 & $0.16: 0.64$ & -1.56 & & 1.31 \\
\hline & 3 & 0.93 & 0.18:0.96 & & & -0.93 & $-0.18:-0.96$ & 2.12 & & -1.65 \\
\hline \multirow{3}{*}{ Klaipeda - Karlshamn } & 1 & 1.12 & 1.14:1.26 & -1.12 & $-1.14:-1.26$ & \multirow{3}{*}{\multicolumn{2}{|c|}{ NA }} & 1.64 & -3.57 & \multirow{3}{*}{ NA } \\
\hline & 2 & -4.12 & $-3.94:-4.54$ & 4.12 & $3.94: 4.54$ & & & -5.85 & -9.09 & \\
\hline & 3 & 2.76 & $2.75: 3.01$ & -2.76 & $-2.75:-3.01$ & & & 3.98 & 14.14 & \\
\hline \multirow{3}{*}{ Dover - Calais } & 1 & -4.8 & $-3.3:-8.3$ & \multirow{3}{*}{\multicolumn{2}{|c|}{ NA }} & 4.8 & 3.3:8.3 & -8.95 & \multirow{3}{*}{ NA } & 10.78 \\
\hline & 2 & -5.3 & $-3.6:-9.1$ & & & 5.3 & 3.6:9.1 & -9.74 & & 11.71 \\
\hline & 3 & -3.6 & $-1.7:-6.9$ & & & 3.6 & $1.7: 6.9$ & -6.91 & & 7.81 \\
\hline
\end{tabular}


The results show an overall agreement of Fuel Case 1 with the actual case where for the examined routes the market share has either increased, or marginally dropped. Considering the significant drop in fuel costs for all routes, it can be derived that the profitability of the service has increased. It is noteworthy that for Fuel Case 1, the model predicts a significant drop in the Dover-Calais service with a modal shift accounting to almost $5 \%$ of the overall freight traffic in the route; or in other words an almost $10 \%$ decrease in the transported lanemeters of the route. This finding is a direct consequence of the significant increase in the freight rates from 2014 to 2015 in the route. Fuel Case 2 shows that if fuel prices return to the 2014 levels for MGO, then the ship operator is worse off in all scenarios. While the loss of cargo is not devastating, considering that most Ro-Ro operators are operating near the breakeven point, even a marginal loss could affect the service. Fuel Case 3 clearly illustrates that if the ship operators were allowed to use HFO, the situation would have been even better for their profitability as the market shares for the ship operator would increase for the first two routes in comparison with the baseline case, whereas for Dover-Calais the drop would not be as high.

For all simulation scenarios, the generalized cost of each option is mainly affected by the freight rates charged. The value of time is important only for very high value cargoes and depreciation rates. As a result, the option of reducing the sailing speed for a route struggling is not expected to have a detrimental effect to the shipper's decision. These options may not be suitable for services that carry high value cargoes, and it may also be difficult for Ro-Pax services as a very long trip may be seen as undesirable by passengers. A final remark is that the service that benefited most from the current low fuel prices is also the service that will be at a greater risk of losing its market share in the event of a significant fuel price increase. These simulation results can therefore be used to examine the vulnerability of services in periods of high fuel prices, and help design efficient contingency measures from the Ro-Ro operators. The presented methodology made use of simulation for various combinations of input parameters due to the lack of exact data on cargo transported in each route, and most importantly market shares on comprehensive O-D pairs. However, there are meaningful conclusions that can still be drawn through this approach as clear patterns can be identified for the different fuel price case studies.

\subsection{Environmental impact of the new sulphur limit}

This section addresses the efficacy of the new limit in reducing emissions based on fuel consumption data provided by the operator. The operator's emissions inventory can be therefore constructed by multiplying the fuel consumption with appropriate emission factors. As these data are treated as confidential, this paper presents a comparison of the total emissions generated between the two years, including illustrative $\mathrm{CO}_{2}$ and $\mathrm{SO}_{2}$ emissions per transported lanemeter-NM for the examined routes. Figure 6 presents the annual emissions based on the actual fuel consumption and transported volumes per quarter. 


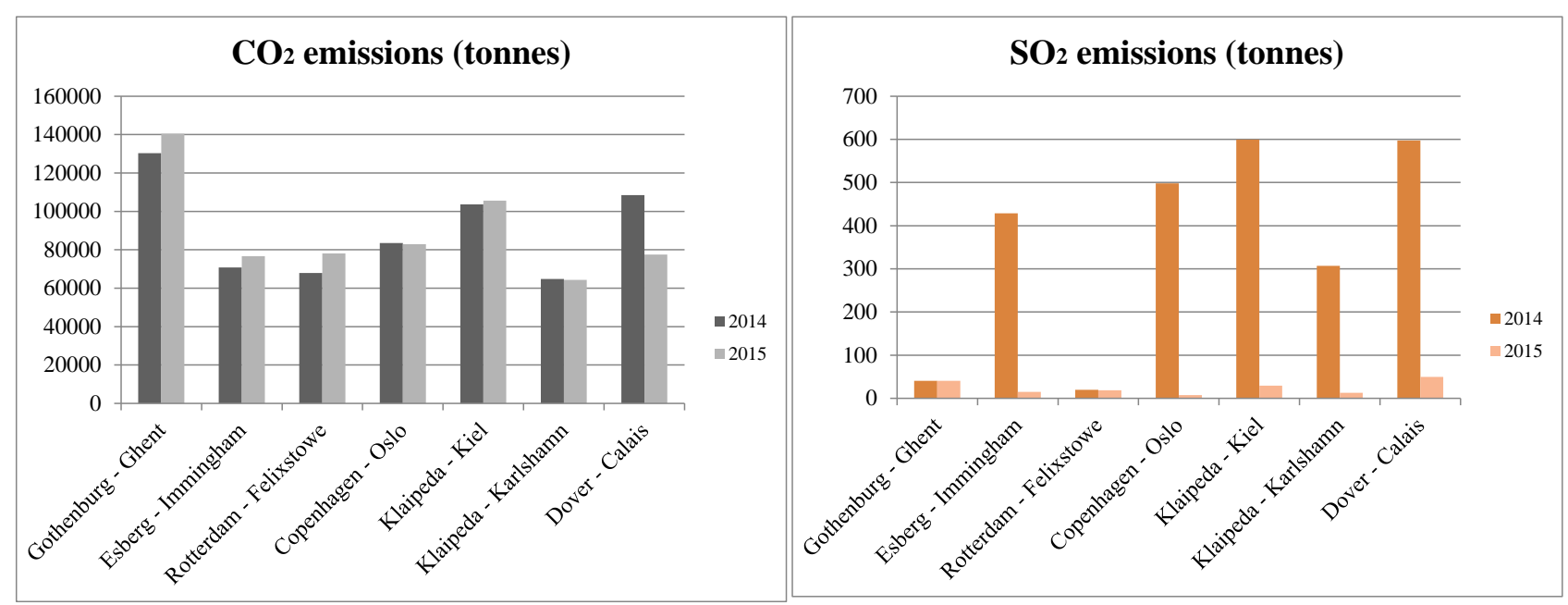

Figure 6: $\mathrm{CO}_{2}$ and $\mathrm{SO}_{2}$ emissions (tonnes) in the examined routes for 2014 and 2015

The results show that the $\mathrm{CO}_{2}$ emissions have not changed dramatically in comparison with 2014 . For most routes there is a slight increase, which can be attributed to a similar increase of trips, a potential increase of sailing speed due to the low fuel prices, the use of MGO which has a higher $\mathrm{CO}_{2}$ emission factor, and the use of scrubbers that are also increasing the fuel demand. A notable decrease can be observed for the Dover-Calais route which is attributed to the significant reduction of sailings due to external events. In terms of $\mathrm{SO}_{2}$ emissions it can be seen that for most routes there has been a detrimental reduction due to the lowered sulphur limit. The only route that does not show a reduction is the Gothenburg Ghent, where all vessels were equipped with scrubbers since the end of 2013. The results in Figure 6 clearly demonstrate that the legislation has had a significant success in reducing sulphur emissions, without triggering a large increase in carbon emissions.

However, it is also important to contrast the emissions intensity of transporting a unit of cargo (a lanemeter of cargo in this case) for one NM, as these routes are not comparable otherwise. Typically, emissions intensity is measured in terms of transported ton-km to facilitate comparisons with different transport modes. As Ro-Ro shipping companies are charging based on the lanemeters that shipments take onboard their vessels, they do not keep track of the weight of each shipment. The MEPC is using an assumption of a 2 ton per $\mathrm{lm}$ in a Ro-Ro vessel (Hjelle and Fridell, 2012) that leads to a $\mathrm{CO}_{2}$ emissions intensity of $49.5 \mathrm{~g} /$ tonne-km which translates into $45.8 \mathrm{~g} / \mathrm{lm}-\mathrm{NM}$-lm. However, these numbers are critically dependent on the load factor of both the vessel, as well as the cargo transported and the load factor of unaccompanied trailers. Figure 7 presents the actual emissions per NM-lm based on the fuel consumption of the vessels in each service, and the number of lanemeter-NM transported. Due to lack of data on the average weight of 1 lanemeter of cargo, comparisons are made in-between the two years in the period of examination.

It has to be noted that for four of the routes, the vessels are also carrying passengers and therefore the emissions allocation should be different. Particularly for Ro-Pax ferries, it is very difficult to allocate emissions among cargo and passengers. There are approaches where emissions are allocated based on the area of the ship allocated to passengers vs the area allocated for cargoes, or where emissions are allocated based on the mass of passengers and cargoes transported. As both approaches are flawed, this paper is considering all emissions being allocated to cargo transported as this is what the framework is modelling. The emissions intensity is expressed in terms of grams of pollutants per lm-NM, and is shown in in Figure 7 for all examined routes. 

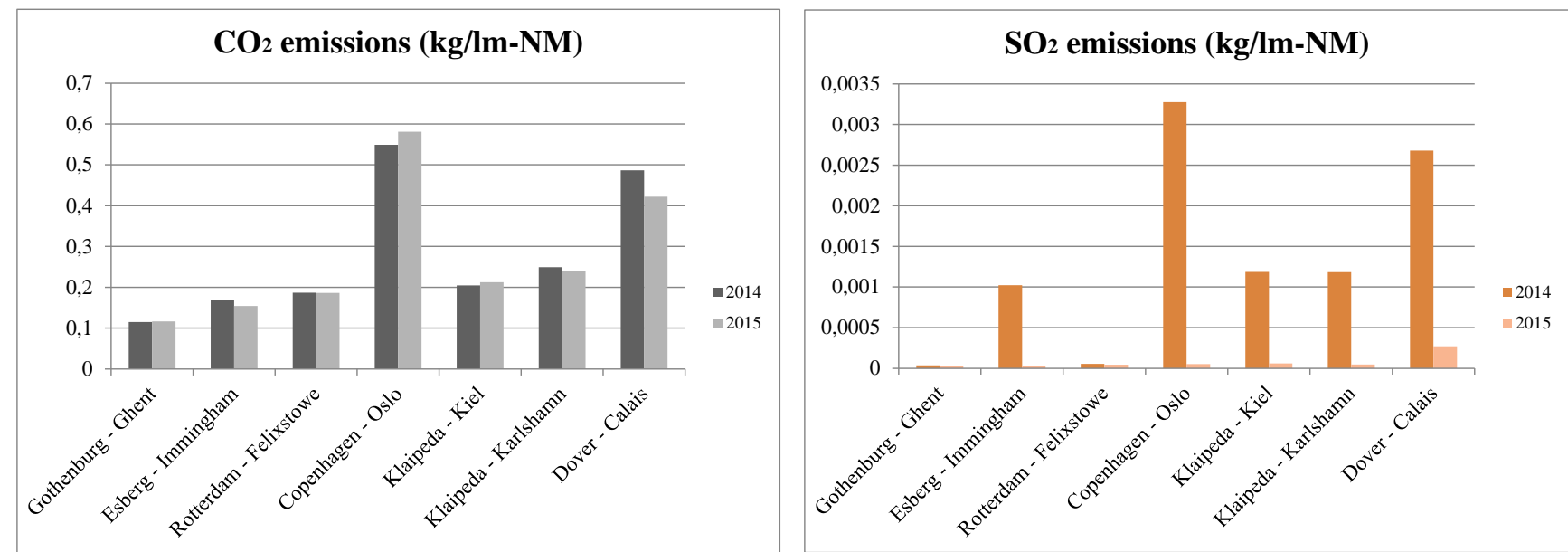

Figure 7: Emissions intensity (kg/lm-NM) for $\mathrm{CO}_{2}$ and $\mathrm{SO}_{2}$ in the examined routes

Figure 7 shows that the carbon emissions intensity for most routes has decreased for all routes with the exception of Klaipeda - Kiel, and Copenhagen - Oslo which shows the highest increase. This shows that despite the overall increase of carbon emissions as evidenced by Figure 6, the shipping company has improved its efficiency. This is mainly due to the increased utilization capacity observed in most routes during 2015, and it could also be a consequence of the deployment of more appropriate vessels for each route. The sulphur dioxide emissions per transported lm-NM are shown to be improving impressively, as expected due to the legislation. The emissions intensity of each route is not easy to compare due to the different mixture of Ro-Pax and Ro-Ro ferries. Routes with high passenger count are showing the highest emissions intensity per lanemeter of cargo, as the emissions are not allocated to passengers. However, one observation can be made that amongst the Ro-Ro routes the longest link shows to be more efficient (Gothenburg - Ghent) which is further enhanced by the fact that the largest vessels are deployed on this service. The two Baltic Ro-Pax routes are showing similar performance as these are served by the same pool of vessels, but again the longest route is performing better. Finally, the highest emissions intensity is observed for the Copenhagen-Oslo route, which can be justified as this is the route with the lowest cargo utilization, and the highest number of passengers whose emissions are also allocated in this calculation on cargoes. Dover - Calais shows the second highest emissions intensity, which is a combination of the high passenger count, and the very short distance and high sailing speeds.

The results of Figure 7 do not allow a direct comparison with other modes, as typically emission intensity is provided with a tonne-km denominator. The weight of cargo is a more significant contributor to the energy requirement for its transportation on road and rail modes, compared with maritime modes. In addition, ferry operators are charging based on the volume transported (freight rates per $\mathrm{lm}$ of cargo) and do not weigh the trailers transported. The comparison of the environmental balance in terms of emissions due to modal shifts is therefore not straightforward. It can however be seen from this analysis that the new sulphur limits have been successful in effectively reducing the sulphur emissions, with a small penalty of increased $\mathrm{CO}_{2}$ emissions. However, this penalty could be higher if the energy of producing low-sulphur fuel was considered in the calculation. In addition, low-sulphur fuel may result in the generation of less PM emissions while scrubber systems are also effective at reducing such pollutant types. Therefore, there are additional benefits associated with the new lower sulphur limit as external costs will be lowered due to the overall reduction of $\mathrm{SO}_{\mathrm{x}}$ and $\mathrm{PM}$ emissions due to shipping. At the same time, the emissions intensity has decreased for all pollutant types as a result of improved vessel deployment and utilization capacity for the ship operator that provided data for this work. A modal shift to other 
modes can lead to decreased utilization rates, and thus constitute short sea shipping less environmentally friendly.

\section{Conclusions}

This paper presented a modelling framework that can be used to explore the repercussions of maritime policy on the freight transportation sector. While there have been previous attempts at estimating the effects on some services through similar policy measures, this is the first attempt to examine the effects of the new SECA limits, and dissect it from the record low fuel prices that were observed in the last two years.

\subsection{Effects of low fuel prices mask the negative effects}

Most services were not negatively affected by the new sulphur limits, and actually improved their performance. It is evident that the actual volumes of transported goods increased for most routes. At the same time, even for some routes that lost some cargoes (due to marginally fewer sailings), the utilized capacity has increased. However, the main reason the Ro-Ro operators seem to be coping with the new limits is the very low prices of fuel experienced throughout 2015.

The model runs conform to the actual case and show small increases in the market shares of the maritime links assuming that the freight rates were lowered more in comparison to land-based modes. In addition, if the regulation was not in place the fuel prices would be much lower as ships would still use HFO. The what-if analysis on using HFO prices in the 2015 levels showed that the market share of the maritime options would have increased further. Thus, the regulation has reduced the rate at which the maritime sector would have increased cargo volumes transported. At the same time, the model identifies a clear risk. Should fuel prices increase, the situation may reverse. The what-if scenarios using higher MGO prices revealed that the Ro-Ro sector would be shrinking and losing cargoes to land-based modes. In that sense, the need to examine measures and policies that would mitigate and reverse such an outcome is still very clear.

\subsection{Further research}

The developed modelling framework allows the estimation of modal shifts as a result of any significant change (on a policy or operational level) that impacts the generalized cost of transport that a shipper is facing in one or more of its alternative transportation options. The framework can be further expanded to consider the implications of the new transport demand for each option following the modelled modal shift. In this way, the modes that are seeing a change in their market shares can alter their price. Therefore, a game theory approach can be conceived whereby the shipping companies that compete for a given transportation demand may change their freight rates following a modal shift attributed to external events (as in this case with the lowering of the sulphur limit).

The methodology is strengthened in the presence of disaggregate level data, but meaningful conclusions can be drawn in cases of less than perfect data sets. In the context of this paper, the focus has been the implications of the lower sulphur limit, however the presented framework can readily consider the impacts of additional changes that affect one or more transport options.

The next steps in this work are concerned with proposing measures from policy makers and ship operators as to mitigate and reverse the modal shifts affecting SSS as a consequence of the relevant regulation. These will revolve around either increasing the generalized cost of competing lessenvironmentally friendly modes, or by decreasing the generalized cost of the affected mode. Introductions of tax levies, imposing speed limits, or provision of subsidies to maritime operators to 
install abatement technologies are some of the measures that will be considered. These results will be reported in future publications.

\section{Acknowledgements}

The work presented in this paper is in the context of the project: "Mitigating and reversing the sideeffects of environmental legislation on Ro-Ro shipping in Northern Europe" funded by the Danish Maritime Fund. The authors would like to thank the two anonymous reviewers for their feedback and comments in improving this manuscript. Finally, the authors are grateful to a manager of the Ro-Ro shipping company whom we worked with in this project, for the provision of data and valuable input in producing this paper, and who wishes to remain anonymous.

\section{REFERENCES}

Bjornland, D. (1993). The importance of short sea shipping in European Transport. ECTM, Short Sea Shipping, Economic Research Center.

Buhaug, Ø., Corbett, J., Endresen, O., Eyring, V., Faber, J., Hanayama, S., Lee, D., Lindstad, H., Mjelde, A., Palsson, C., Wanquing, W., Winebrake J. and Yoshida, K. (2009) Second IMO Greenhouse Gas Study. International Maritime Organization, London

Cullinane, K. and Bergqvist, R. (2014). Emission control areas and their impact on maritime transport. Transportation Research Part D: Transport and Environment, 28, 1-5.

de Boer E., Ahdour S., and Meerwaldt H. (2016). SECA Assessment: Impacts of 2015 SECA marine fuel sulphur limits. Available at:

https://www.nabu.de/imperia/md/content/nabude/verkehr/nabu-seca-studie2016.pdf Accessed (May 2016)

de Dios Ortúzar, J., \& Willumsen, L. G. (1994). Modelling transport. New Jersey: Wiley.

European Commission (2005). Directive 2005/33/EC of the European Parliament and of the Council amending Directive 1999/32/EC as regards the sulphur content of marine fuels

,” Official Journal of the European Union, 2005 available at: http://eur-lex.europa.eu/legalcontent/EN/TXT/PDF/?uri=CELEX:32005L0033\&from=EN (accessed May 2016)

European Commission (2013). Integrating maritime transport emissions in the EU's greenhouse gas reduction policies. Available at: http://eur-lex.europa.eu/legal-

content/EN/TXT/PDF/?uri=CELEX:52013DC0479\&from=en (accessed September 2016)

European Commission (2015). EU transport in figures, Statistical Pocketbook 2015. Available at: http://ec.europa.eu/transport/sites/transport/files/pocketbook2015.pdf (accessed August 2016)

Eurostat (2015). Energy, transport and environment indicators, 2015 edition.

Available at:

http://ec.europa.eu/eurostat/documents/3217494/7052812/KS-DK-15-001-EN-N.pdf/eb9dc93d-

8abe-4049-a901-1c7958005f5b (Accessed August 2016) 
Eurostat (2016). Maritime ports freight and passenger statistics. Available at: http://ec.europa.eu/eurostat/statisticsexplained/index.php/Maritime_ports_freight_and_passenger_statistics (Accessed September 2016)

Eyring V., Köhler H.W., van Aardenne J. and Lauer A. (2005) Emissions from international shipping: 1. The last 50 years. Journal of Geophysical Research: Atmospheres 110(D17)

Fagerholt, K., \& Psaraftis, H. N. (2015). On two speed optimization problems for ships that sail in and out of emission control areas. Transportation Research Part D: Transport and Environment, 39, 56-64.

IMO (2008). Revised MARPOL Annex VI: Regulations for the prevention of air pollution from ships and NOx technical code London: IMO Marine Environmental Protection Committee (MEPC).

IMO (2014). Third IMO GHG Study 2014. International Maritime Organization (IMO), London. Available at: http://www.iadc.org/wp-content/uploads/2014/02/MEPC-67-6-INF3-2014-FinalReport-complete.pdf [accessed June 2015]

International Energy Agency (2014). $\mathrm{CO}_{2}$ emissions from fuel combustion. Highlights. Available at:

https://www.iea.org/publications/freepublications/publication/CO2EmissionsFromFuelCombustion Highlights2014.pdf [accessed May 2016]

Hjelle, H. M., \& Fridell, E. (2012). When is short sea shipping environmentally competitive?. INTECH Open Access Publisher.

Jiang, L., Kronbak, J., \& Christensen, L. P., (2014). The costs and benefits of sulphur reduction measures: Sulphur scrubbers versus marine gas oil. Transportation Research Part D: Transport and Environment, 28, 19-27

Lemper, B., Hader, A., Hübscher, A., Maatsch, S., \& Tasto, M. (2009). Reducing the sulphur conten of shipping fuels further to $0.1 \%$ in the North Sea and Baltic Sea in 2015: Consequences for shipping in this shipping area. Final report. Institut für Seeverkehrswirtschaft und Logistik. Bremen.

Ng, A. K., Sauri, S., \& Turró, M. (2013). Short sea shipping in Europe: issues, policies and challenges. Regulating Transport in Europe, 196.

Odgaard, T., Frank, C., Henriques, M., and Bøge, M. (2013). The impact on short sea shipping and the risk of modal shift from the establishment of a NOx emission control area in the North Sea. Available at: http://eng.mst.dk/media/mst/9149808/theimpactonshortseashippingandtheriskofmodalshiftfromthee stablishmentofanecafina. (accessed April 2016)

Notteboom, T., Delhaye, E., \& Vanherle, K. (2010). Analysis of the consequences of low sulphur fuel requirements. ITMMA-Universiteit Antwerpen Transport\&Mobility. 
Panagakos, G. P., Stamatopoulou, E. V., \& Psaraftis, H. N. (2014). The possible designation of the Mediterranean Sea as a SECA: A case study. Transportation Research Part D: Transport and Environment, 28, 74-90.

Psaraftis, H. N., \& Kontovas, C. A. (2010). Balancing the economic and environmental performance of maritime transportation. Transportation Research Part D: Transport and Environment, 15(8), 458-462.

United Nations Conference on Trade and Development (2014) Review of maritime transport. UNCTAD/RMT/2014, United Nations publication.

http://unctad.org/en/PublicationsLibrary/rmt2014_en.pdf, accessed June 2015

Verhoeven, P. (2015). Report on online survey of ship operators. ECSA, 24 March 2015

Zis, T., North, R. J., Angeloudis, P., Ochieng, W. Y., \& Bell, M. G. (2015). Environmental balance of shipping emissions reduction strategies. Transportation Research Record: Journal of the Transportation Research Board, (2479), 25-33.

Zis, T., Angeloudis, P., Bell, M. G., \& Psaraftis, H. N. (2016). Payback Period for Emissions Abatement Alternatives: The Role of Regulation and Fuel Prices. In Transportation Research Record (In-press). 